\title{
INFLUENCE OF NATURAL AND SYNTHETIC ORGANIC LIGANDS ON THE STABILITY AND MOBILITY OF REDUCED TC(IV)
}

\author{
Nathalie A. Wall (PI) ${ }^{(1)}$ and Baohua Gu ${ }^{(2)}$ \\ (1) Washington State University - Chemistry Department - nawall@wsu.edu \\ (2) Oak Ridge National Laboratory - Environmental Sciences Division - gub1@ornl.gov
}

This is the final report for the work performed by Prof. Nathalie A. Wall (PI, WSU), Dr. Baohua Gu (ORNL), and their respective research team, under the funding opportunity DE-PSO207ER07-18. This is work started at the end of 2008.

\section{INTRODUCTION}

The original goal of this work was to better understand the fate and transport of reduced uranium (U(IV)) and technetium (Tc(IV)) to design better strategies for the remediation of contaminated DOE sites, where a number of natural and synthetic organic ligands commonly co-exists with the contaminant. The scope of the work was to quantify the influence of soluble organic ligands in Tc(IV) and U(IV) solubilities. However, in agreement with DOE managers, the scope of the work quickly changed to focus on Tc(IV) chemistry. The primary objectives were (1) to quantify the interactions of organic ligands with Tc(IV) through the generation of thermodynamic (complexation) and kinetic parameters needed to assess and predict the mobility of reduced Tc(IV) at DOE contaminated sites; and (2) to determine the impact of organic ligands on the mobility and fate of reduced Tc(IV) under field geochemical conditions.

\section{RESULTS:}

\section{Determination of Tc(IV) complexation and binding constants with organic ligands:}

Stability constants of Tc(IV) complexes with different soluble organic ligands were determined using a solvent extraction technique. The experiments were performed over a wide range of ionic strengths (typically from $0.5 \mathrm{M}$ to $3 \mathrm{M}$ ), to allow for the determination of the stability constants at zero ionic strength, using the Specific Ion Interaction Theory (SIT). Data at zero ionic strength are of particular important, because they can be directly integrated into geochemical codes, such as PHREEQC. The results describing the determination of the stability constants of the complexes formed between acetate and Tc(IV) were published in Radiochimica Acta (Boggs et al., 2010) and presented at the 2009 Migration international meeting. The work performed to determine the binding constants of the complexes formed between different humic and fulvic acids and Tc(IV) was published in Environmental Science and Technology (Boggs et al., 2011b) and different aspects of the studies presented at the 2010 ACS Spring National Meeting, the 2010 ACS/NORM Regional meeting, and 2010 PACIFICHEM conference. In this particular work, a variety of humic substances were studied: Oak Ridge Field Research Center humic and fulvic acids (FRCHA and FRCFA), purified Sigma Aldrich humic acids (SAHA), Elliot Soil humic acids (ESHA) - these studies also required to determine pKa values and carboxylic capacity for each humic substance. A paper describing the complexation of Tc(IV) with ethylenediaminetetraacetate (EDTA) has been submitted in November 2011 to Radiochimica Acta (Boggs et al., 2011a), while a paper on the citrate complexation with Tc(IV) is in preparation (Wall and Karunathilake, 2011) and will be submitted 
for publication by the end of 2011 calendar year. For all systems, experiments were performed at $\mathrm{pH} 4.5$ and 7 , allowing for the determination of the complexation of $\mathrm{TcO}(\mathrm{OH})^{+}$and $\mathrm{TcO}(\mathrm{OH})_{2}{ }^{0}$, because $\mathrm{TcO}(\mathrm{OH})_{2}{ }^{0}$ is the predominant species at $\mathrm{pH}$ 7 , while it is present along with $\mathrm{TcO}(\mathrm{OH})^{+}$at $\mathrm{pH} 4.5$, as indicated by the speciation calculated using the PHREEQC code, presented by Figure 1.

Values for stability constants and binding constants are shown in Table 1 traditionally the equilibrium constant for the metal binding with humic substances is not classified as "stability constant" (unlike with carboxylic acids, such as acetate), because

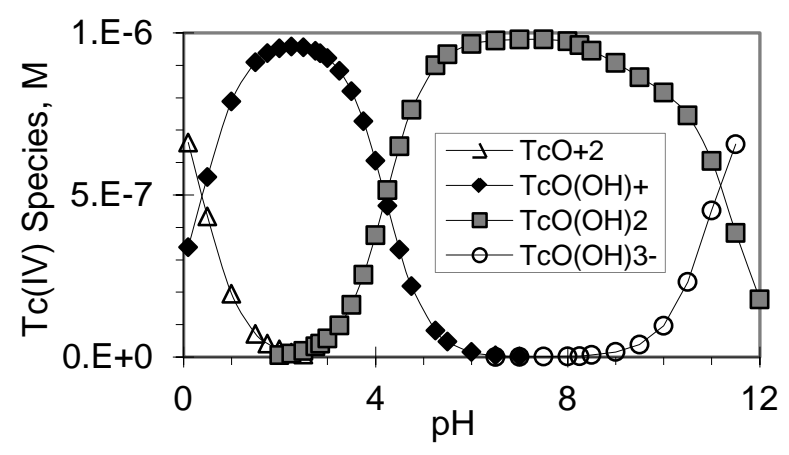

Figure 1. Tc(IV) speciation (Boggs et al., 2010)

the nature of the bond has not been clarified; humic equilibrium constants are therefore called "binding constant" (Choppin and LabonneWall, 1997). Also, because of the uncertainty regarding the nature of humic bonds with metals, the SIT modeling was not applied to our results to deduct any value at zero ionic strength. Stability constants increase by several orders of magnitude from acetate, to citrate, to EDTA complexes, due to the increase of the number of carboxylic group, as observed for other metals (Smith et al., 1997). Although acetate does not bind to the neutral $\mathrm{TCO}(\mathrm{OH})_{2}{ }^{0}$ species, citrate, EDTA, and humic substances do, with a stability constants lower than for the complexation of $\mathrm{TCO}(\mathrm{OH})^{+}$. Additionally, calculations indicate that the strength of EDTA complex allow for the dissociation of the hydroxide groups from the $\mathrm{TcO}(\mathrm{OH})^{+}$and $\mathrm{TcO}(\mathrm{OH})_{2}{ }^{0}$ species and bind directly to $\mathrm{TcO}^{2+}$; no such behavior could be demonstrated for acetate and citrate complexes. The binding constants of the humic substances remain constant within errors, regardless of the origin or type of humic, as was found for the humic binding to actinides (LabonneWall et al., 1996). However, the actinide binding constants to humic acids were found to be consitantly one order or magnitude higher than those with fulvic acids, while we found that Tc(IV) binding constants are equivalent between humic and fulvic acids. It is unsure at this point if our results reflect an anomaly of the particular Field Research Center Fulvic Acids (FRCFA) or a larger trend of the transition metals. The binding of additional fulvic acids would help to ensure that the FRCFA are representative of fulvic acids, in general. Finally, data show similarity between humic binding constants and citrate stability constants, a trend previously observed for actinides binding with humics (Wall et al., 2002).

A new solvent extraction method to separate $\mathrm{Tc}(\mathrm{VII})$ from $\mathrm{Tc}(\mathrm{IV})$ was developed to ensure that Tc was maintain in its tetravalent state during the course of the experimental work. Results are presented in a paper currently in preparation (Boggs et al., 2012a) that will be submitted at the beginning of the 2012 calendar year. 
Wall - Gu. Annual Report 2011. Project ID 0014587; Award Register\#: ER64696

Table 1. Examples of Tc(IV) complexation/binding constants with soluble organic ligands, at $0 \mathrm{M}$ ionic strength.

\begin{tabular}{|c|c|c|c|c|}
\hline Ionic strength & Ligand & Equilibrium & $\begin{array}{l}\text { Equilibrium constant } \\
\text { (log unit) }\end{array}$ & Ref. \\
\hline $0 \mathrm{M}$ & Acetate & $\mathrm{TcO}(\mathrm{OH})^{+}+\mathrm{Ac}^{-} \rightleftharpoons \mathrm{TcO}(\mathrm{OH}) \mathrm{Ac}$ & $2.8 \pm 0.3$ & [1] \\
\hline $0 \mathrm{M}$ & Citrate & $\mathrm{TcO}(\mathrm{OH})^{+}+\mathrm{Cit}^{3-} \rightleftharpoons \mathrm{TcO}(\mathrm{OH}) \mathrm{Cit}^{2-}$ & $7.5 \pm 0.3$ & [2] \\
\hline $0 \mathrm{M}$ & & $\mathrm{TcO}(\mathrm{OH})_{2}^{0}+\mathrm{Cit}^{3-} \rightleftharpoons \mathrm{TcO}(\mathrm{OH})_{2} \mathrm{Cit}^{3-}$ & $2.8 \pm 0.2$ & [2] \\
\hline $0 M$ & EDTA & $\mathrm{TcO}^{2+}+\mathrm{EDTA}^{4-} \rightleftharpoons \mathrm{TcOEDTA}^{2-}$ & $20.0 \pm 0.4$ & [3] \\
\hline $0 \mathrm{~m}$ & & $\mathrm{TcO}^{2+}+\mathrm{H}^{+}+\mathrm{EDTA}^{4-} \rightleftharpoons \mathrm{TcOHEDTA}^{-}$ & $25.3 \pm 0.5$ & [3] \\
\hline $0.5 \mathrm{M}$ & FRCHA & $\mathrm{TcO}(\mathrm{OH})^{+}+\mathrm{HA} \rightleftharpoons \mathrm{TcO}(\mathrm{OH}) \mathrm{HA}$ & $6.8 \pm 0.3$ & {$[4]$} \\
\hline $0.5 \mathrm{M}$ & FRCHA & $\mathrm{TcO}(\mathrm{OH})_{2}{ }^{0}+\mathrm{HA} \rightleftharpoons \mathrm{TcO}(\mathrm{OH})_{2} \mathrm{HA}$ & $3.9 \pm 0.3$ & {$[4]$} \\
\hline $0.5 \mathrm{M}$ & FRCFA & $\mathrm{TcO}(\mathrm{OH})^{+}+\mathrm{FA} \rightleftharpoons \mathrm{TcO}(\mathrm{OH}) \mathrm{FA}$ & $6.8 \pm 0.4$ & [4] \\
\hline $0.5 \mathrm{M}$ & FRCFA & $\mathrm{TcO}(\mathrm{OH})_{2}{ }^{0}+\mathrm{FA} \rightleftharpoons \mathrm{TcO}(\mathrm{OH})_{2} \mathrm{FA}$ & $4.3 \pm 0.4$ & {$[4]$} \\
\hline $0.5 \mathrm{M}$ & SAHA & $\mathrm{TcO}(\mathrm{OH})^{+}+\mathrm{HA} \rightleftharpoons \mathrm{TcO}(\mathrm{OH}) \mathrm{HA}$ & $6.7 \pm 0.2$ & [4] \\
\hline $0.5 \mathrm{M}$ & SAHA & $\mathrm{TcO}(\mathrm{OH})_{2}{ }^{0}+\mathrm{HA} \rightleftharpoons \mathrm{TcO}(\mathrm{OH})_{2} \mathrm{HA}$ & $4.3 \pm 0.3$ & {$[4]$} \\
\hline $0.5 \mathrm{M}$ & ESHA & $\mathrm{TcO}(\mathrm{OH})_{2}{ }^{0}+\mathrm{HA} \rightleftharpoons \mathrm{TcO}(\mathrm{OH})_{2} \mathrm{HA}$ & $4.6 \pm 0.1$ & [4] \\
\hline
\end{tabular}

[1] (Boggs et al., 2010)

[2] (Wall and Karunathilake, 2011)

[3] (Boggs et al., 2011a)

[4] (Boggs et al., 2011b)

The quantification of Tc(IV) complexation with soluble organic ligands, as described above, is of particular interest because ligand complexation lead to an increase of the Tc(IV) solubility. PHREEQC calculations, using the stability constants generated via this work, allowed to show such increase. Figure 2 shows that an increase of acetate from $0 \mathrm{M}$ to $20 \mathrm{mM}$ lead to an increase of $\mathrm{Tc}(\mathrm{IV})$ solubility from $5 \cdot 10^{-9} \mathrm{M}$ to $10^{-8} \mathrm{M}$, at $\mathrm{pH} 4.5$. However, minute amount of EDTA lead to an even greater Tc(IV) dissolution; Figure 3 shows that $2.5 \mathrm{mM}$ EDTA lead to $7( \pm 5) \cdot 10^{-7} \mathrm{M}$ dissolved Tc(IV), a dissolved Tc concentration two order of magnitude larger than in absence of complexing ligand. Figure 4 and Figure 5 present Tc speciation in the presence of humic acid and EDTA, respectively. Complexed Tc(IV) are the predominant species: in presence of humic acids, the predominant species are $\mathrm{TcO}(\mathrm{OH})-\mathrm{HA}$ and $\mathrm{TcO}(\mathrm{OH})_{2} \mathrm{HA}$, at $\mathrm{pH}$ below and above 6.2, respectively; in the presence of EDTA, the predominant species are TCOEDTA and TCOHEDTA, at pH lower than 3.5 and in the 3.5-7.25 pH range, respectively. 


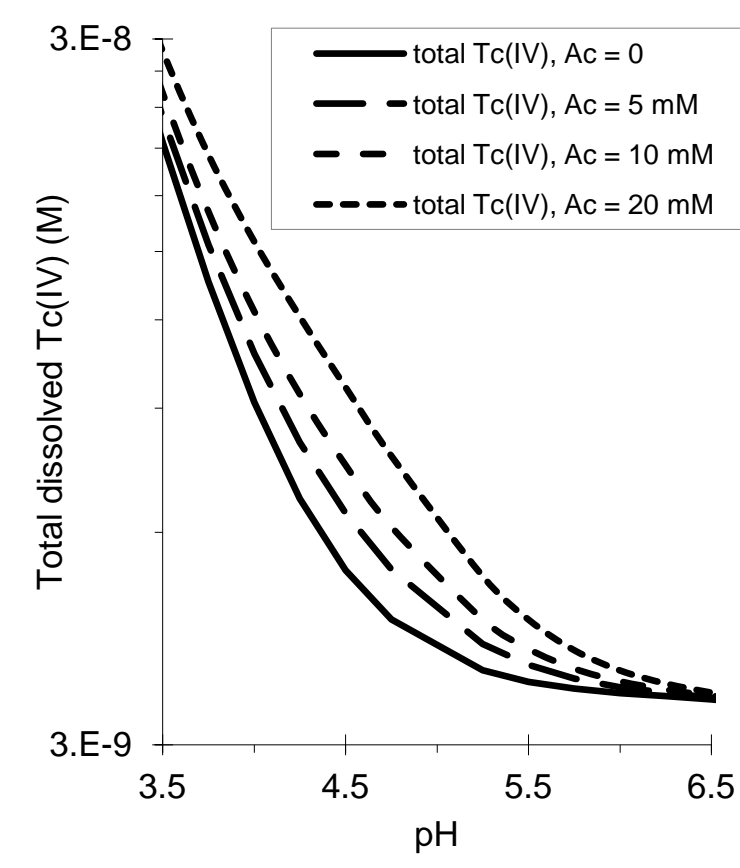

Figure 2. Modeled solubility of $\mathrm{Tc}(\mathrm{IV}) \mathrm{O}_{2} \cdot 1.6 \mathrm{H}_{2} \mathrm{O}$ in presence varying amount of acetate. (Boggs et al., 2010)

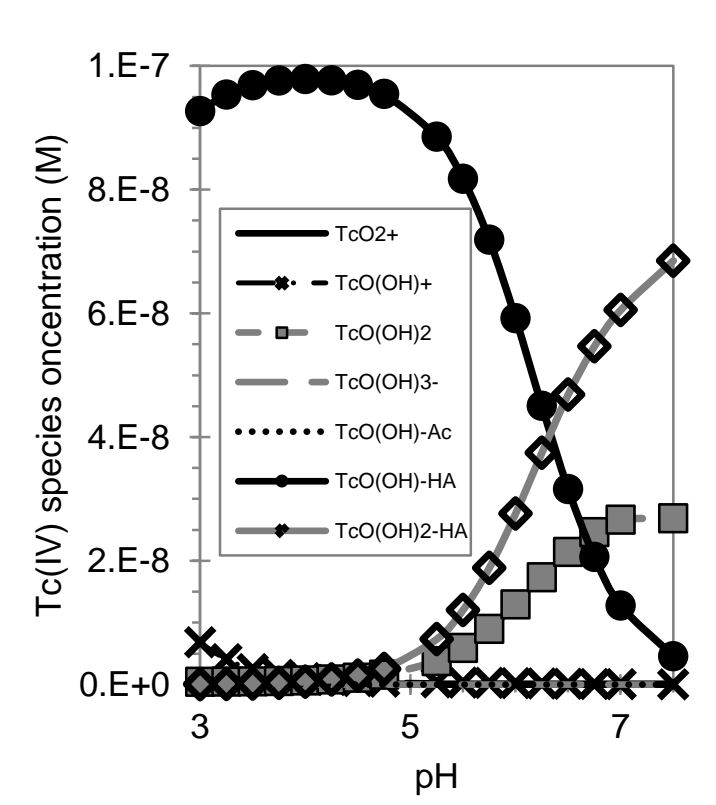

Figure 4. Tc(IV) speciation in the presence of 20 ppm FRCHA. (Boggs et al., 2011b)

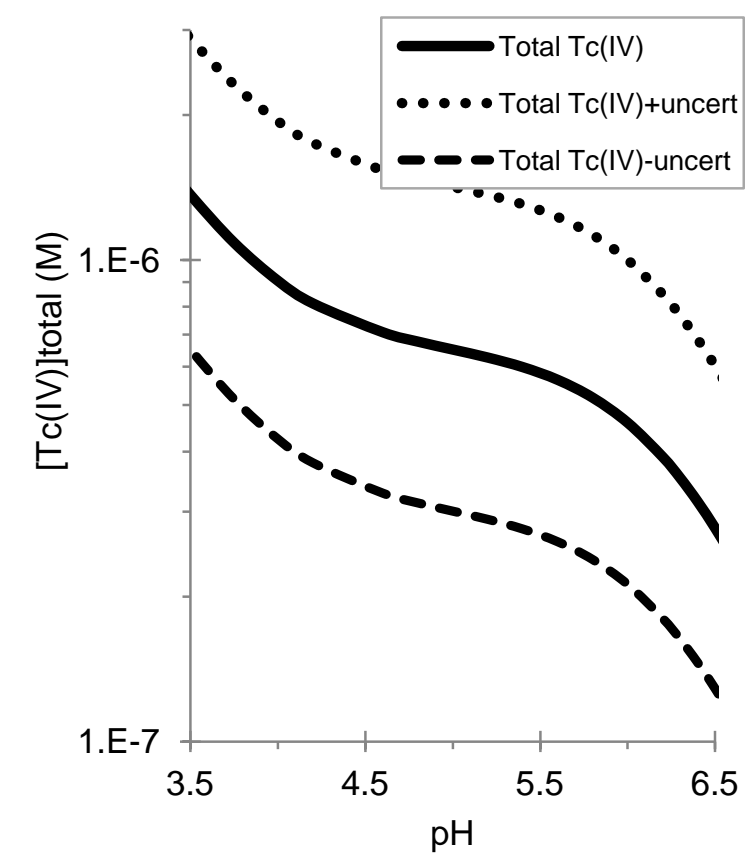

Figure 3. Modeled solubility of Tc(IV) in presence of $2.5 \mathrm{mM}$ EDTA. (Boggs et al., 2011a)

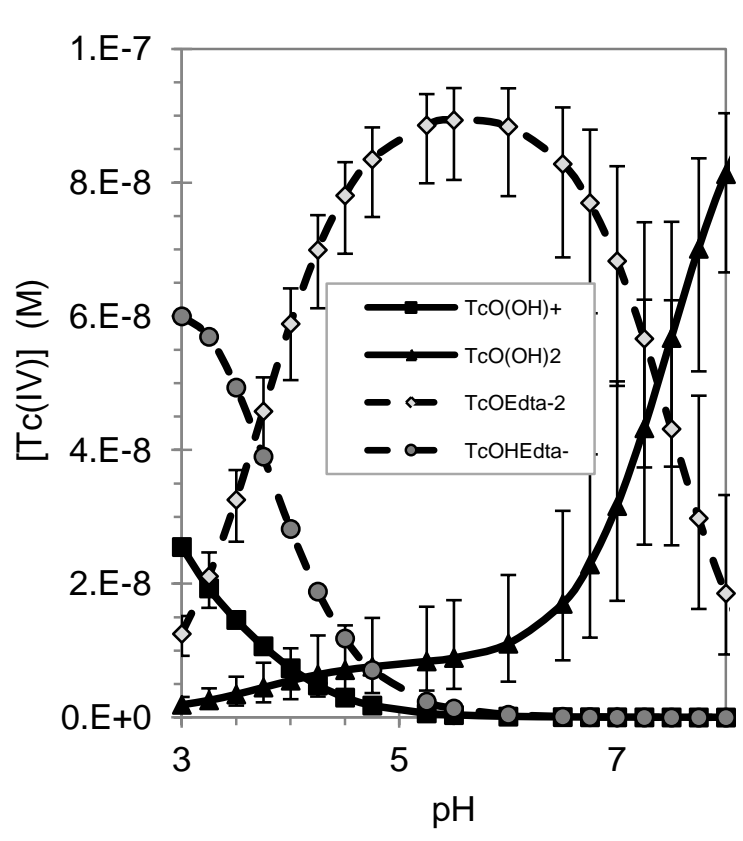

Figure 5. Modeled speciation of Tc(IV) in presence of $0.17 \mathrm{mM}$ EDTA. (Boggs et al., 2011a) 
Wall - Gu. Annual Report 2011. Project ID 0014587; Award Register\#: ER64696

\section{Ligand-promoted dissolution:}

This study was undertaken to experimentally determine the effects of a synthetic organic ligand, EDTA, and two natural humic isolates on the dissolution and solubility of Tc(IV) oxides. Pure synthetic $\mathrm{TcO}_{2} \cdot n \mathrm{H}_{2} \mathrm{O}(0.23 \mathrm{mM})$ was used, and its dissolution kinetics measured at $\mathrm{pH} \sim 6$ under both reducing and oxidizing environments. All organic ligands were found to enhance the dissolution of $\mathrm{Tc}(\mathrm{IV})$ oxides from $\sim 10^{-8} \mathrm{M}$ (without ligands) up to $4 \cdot 10^{-7} \mathrm{M}$ under a strict anaerobic condition, a value in agreement with the PHREEQC calculations presented with Figure 5, which shows that the addition of the smaller concentration of $0.17 \mathrm{mM}$ EDTA leads to a dissolved Tc(IV) concentration of $9 \cdot 10^{-8} \mathrm{M}$. Reduced Tc(IV) was also found to re-oxidize rapidly under oxic conditions with an observed oxidative dissolution rate about an order of magnitude higher than that of the ligand-promoted dissolution under reducing conditions. Interestingly when compared with controls, EDTA decreased the oxidative dissolution, whereas humic acid increased the dissolution possibly due to its redox functional properties which could facilitate intra-molecular electron transfer under oxic conditions. Our results highlight the importance of such complex interactions which may have on the stability and mobility of Tc, thereby affecting its long-term fate at contaminated environments. This work was presented at the 2010 Goldschmidt conference and published in Environmental Science and Technology (Gu et al., 2011)

\section{HS size exclusion}

The binding of Tc(IV) with different HA size fractions was also quantified, using HA from two sources (purified Sigma Aldrich and IHSS Elliot Soil). The concentration of size fractions depends on $\mathrm{pH}$, ionic strength, and the origin of the humics, as expected (Wall and Choppin, 2003). While purified Sigma Aldrich humic acids are present as a variety of sizes (10 nm to $>1 \mu \mathrm{m}$ ) at lower ionic strengths (e.g. $0.1 \mathrm{M}$ ), while HA size is predominantly larger than $1 \mu \mathrm{m}$ at $1.0 \mathrm{M}$ ionic strength. The zeta potential of the overall humic acid solution is mainly driven by the behavior of the particles larger than $750 \mathrm{~nm}$; the zeta potential remained constant at ca. $40 \mathrm{MV}$ for size fractions smaller than $750 \mathrm{~nm}$. Tc(IV) tracer concentration does not affect HA size distribution and is bound to the HA size fractions that are predominant in the experimental conditions. However, for HA fractions smaller than $750 \mathrm{~nm}$, Tc binding is not always linearly correlated to HA concentrations; for example, a larger fraction of Tc is bound to the 150-250 nm fraction than the $10-50 \mathrm{~nm}$ one, at $\mathrm{pH} 7$, while $\mathrm{HA}$ is more abundant in the second fraction. Different aspects of these data were presented at the National ACS meeting (Denver, August 2011) and the Migration'11 conference (China, September 2011). A journal article is also in preparation (Boggs et al., 2012b) and will be submitted for publication in a peer-review journal, early in the 2012 calendar year.

\section{MAJOR ACCOMPLISHMENTS AND DELIVERABLES:}

(Research Assistant $^{@}$, Graduate Student ${ }^{\#}$, Undergraduate Student ${ }^{\$}$ )

\section{Education:}

This project has allowed for the training of 3 post-doctoral research associates, 3 graduate students, and 3 undergraduate students. 
Wall - Gu. Annual Report 2011. Project ID 0014587; Award Register\#: ER64696

\section{Publications:}

1. Interactions of $\mathrm{Tc}(\mathrm{IV})$ with citrate in $\mathrm{NaCl}$ media. Nathalie A. Wall. And Nelum Karunathilake $^{\#}$ In preparation.

2. $\mathrm{Tc}(\mathrm{VII}) / \mathrm{Tc}(\mathrm{IV})$ separation technique. Boggs $M \mathrm{~A}^{\#}$, Gribat $\mathrm{L}^{\#}$, Boele $\mathrm{C}^{\#}$, Wall NA. In preparation.

3. Size fractionated complexation of Tc(IV) with soil humic acids at varying solution conditions: correlations and observations from zeta potential, dynamic light scattering, ATR-IR, and NMR. Boggs M.A.", Nulle S.E. ${ }^{\$}$ and Wall N.A. (2011) In preparation.

4. Complexation of $\mathrm{Tc}(\mathrm{IV})$ with EDTA at varying ionic strength of $\mathrm{NaCl}$. Boggs M.A. , Islam M. ${ }^{@}$, and Wall N.A. Submitted.

5. Dissolution of Technetium(IV) Oxide by Natural and Synthetic Organic Ligands under both Reducing and Oxidizing Conditions. Gu, Dong ${ }^{\circledR}$, Liang ${ }^{\circledR}$, and Wall. Environmental Science \& Technology. 45(11), 4771-4777 (2011)

6. Interactions of Tc(IV) with Humic Substances. Boggs ${ }^{\#}$, Minton $^{\$}$, Dong $^{@}$, Lomasney $^{\$}$, Islam $^{@}$, Gu, and Wall. Environmental Science and Technology. 45(7), 2718-2724 (2011)

7. Complexation of Tc(IV) with acetate at varying ionic strengths. Boggs ${ }^{\#}$, Dong ${ }^{@}$, Gu, and Wall. Radiochimica Acta. 98, 583-587 (2010).

\section{Presentations at conferences:}

1. "Size Discriminated Complexation of Tc(IV) with Humic Acid at Varied Ionic Strengths of NaCl". Boggs ${ }^{\#}$ and Wall Migration '11, Sept. 2011, Beijing, China.

2. "Zeta potential of humic acids of different sizes and correlation with $\mathrm{Tc}(\mathrm{IV})$ complexation, at varying ionic strength". Boggs ${ }^{\#}$ and Wall ACS National Meeting, Aug.-Sep., 2011, Denver, USA.

3. "Stability of tetravalent technetium in presence of natural and synthetic organic ligands". Wall and Gu Invited presentation. PACIFICHEM 2010, Dec. 2010, Honolulu, HI, USA.

4. "Humic Acid Complexation with Tc(IV)". Boggs", Minton $\$$, Lomasney $\$$, Wall. ACS/NORM regional meeting, Jun. 2010, Pullman, WA, USA.

5. "Radionuclide environmental behaviors: An overview". Wall N.A. Invited presentation. ACS/NORM regional meeting, Jun. 2010, Pullman, WA, USA.

6. "Effect of natural humic substances on the dissolution and stability of reduced technetium and uranium". Gu, Dong ${ }^{@}$ Wall, Lou $^{@}$. Goldschmidt, Jun. 2010, Knoxville, TN, USA.

\section{RELATED URL AT INSTITUTION:}

http://analytical.chem.wsu.edu/faculty/walln

\section{LITERATURE CITED}

Boggs MA, Dong W, Gu B, Wall NA. Complexation of Tc(IV) with acetate at varying ionic strength. Radiochimica Acta 2010; 98: 583-587.

Boggs MA, Gribat L, Boele C, Wall NA. Tc(VII)/Tc(IV) separation technique. in preparation 2012a.

Boggs MA, Islam MR, Dong W, Wall N. Complexation of Tc(IV) with EDTA at varying ionic strength of $\mathrm{NaCl}$. Submitted 2011a. 
Boggs MA, Minton T, Dong W, Lomasney S, Islam MR, Gu B, et al. Interactions of Tc(IV) with Humic Substances. Environ. Sci. Technol. 2011b; 45: 2718-2724.

Boggs MA, Nulle SE, Wall NA. Size fractionated complexation of Tc(IV) with soil humic acids at varying solution conditions: correlations and observations from zeta potential, dynamic light scattering, ATR-IR, and NMR. in preparation 2012b.

Choppin GR, LabonneWall N. Comparison of two models for metal-humic interactions. Journal of Radioanalytical and Nuclear Chemistry 1997; 221: 67-71.

Gu B, Dong W, Liang L, Wall NA. Dissolution of Technetium(IV) Oxide by Natural and Synthetic Organic Ligands under both Reducing and Oxidizing Conditions. Environ. Sci. Technol. 2011; 45: 4771-4777.

LabonneWall NA, Choppin GR, Monsallier JM. Interaction of actinides with humic and fulvic acids at high ionic strengths. Abstracts of Papers of the American Chemical Society 1996; 212: 100-NUCL.

Smith RM, Martell A, Motekaitis R. NIST Critically Selected Stability Constants of Metal Complexes Database. Version 4.0. User's Guide. 46. NIST Standard Reference Database 46, National., 1997.

Wall NA, Borkowski M, Chen JF, Choppin GR. Complexation of americium with humic, fulvic and citric acids at high ionic strength. Radiochimica Acta 2002; 90: 563-568.

Wall NA, Choppin GR. Humic acids coagulation: influence of divalent cations. Applied Geochemistry 2003; 18: 1573-1582.

Wall NA, Karunathilake N. Interactions of Tc(IV) with citrate in $\mathrm{NaCl}$ media. in preparation 2011. 